\title{
Design a Four Dual polarizations MIMO System Based a Serrated Chord with Right Angle Triangle Shape
}

\author{
$1^{\text {st }}$ Nada M. Khalil Al-Ani ${ }^{1}, 2^{\text {nd }}$ Oras A. Shareef Al-Ani ${ }^{2}, 3^{\text {rd }}$ Mahmood F. Mosleh ${ }^{3}$ and $4^{\text {th }}$ \\ Read A. Abd-Alhameed ${ }^{4}$ \\ \{ eng.nada1985@gmail.com ${ }^{1}$, oras.a.s.alani@gmail.com² ${ }^{2}$ drmahfa@yahoo.com ${ }^{3}$, \\ r.a.a.abd@bradford.ac.uk $\left.{ }^{4}\right\}$
}

\author{
Computer Engineering Techniques Middle Technique University Baghdad, Iraq ${ }^{1,2,3}$, School of \\ Engineering and Informatics University of Bradford Bradford, $\mathrm{Uk}^{4}$
}

\begin{abstract}
MIMO antenna is the future elements which will operate with the $5 \mathrm{G}$ smartphone devices. In this research, a model of MIMO system of four elements each has a dual-polarized port is proposed. In order to approach a preferred model to match the future application of wireless, two right-angle triangles with chord have a serrated shape is proposed. The partial ground is segmented to four elements corresponding to each proposed single antenna with a suitable shape. The results show that the operating frequency of each single antenna is $6.27 \mathrm{GHz}$ and can cover $590 \mathrm{MHz}(5.97 \mathrm{GHz}-6.56$ $\mathrm{GHz}$ ) at $-10 \mathrm{~dB}$ with good isolation $-26 \mathrm{~dB}$ while the MIMO system operated at $6.13 \mathrm{GHz}$ with $500 \mathrm{MHz}$ covered a range of $(5.9-6.4) \mathrm{GHz}$.
\end{abstract}

Keywords: Serrated, dual-polarized, right-angle triangle, MIMO array, partial ground.

\section{Introduction}

Lately, as the fourth generation of mobile communications (4G) have fully developed physically, the concentration of many institutions have moved out forward fifth-generation of mobile communication (5G) [1]. As it is known, the essencely index of the future 5G communication is the hugely amount of the data transfer [2]. So, the main challenge of the designer is to improve the data rate for $5 \mathrm{G}$ smartphone applications. To improve the efficient spectrum without increasing input power, multiple-input multiple-output (MIMO) is a good choice to investigate such enhancement [3]. Antenna diversity with MIMO system can also provide an improvement in coverage and quality. Because of the printed circuit board (PCB) of the smart phone favored to be as small as possible, polarization techniques have been introduced. The power of the received signal is increased by utilizing the dual-polarization at the same time can mitigate the fading effects of the multipath [3]. However, with MIMO system the surface currents and due to its radiation resulted in a mutual coupling problem [4]. To address the mutual coupling problem, many techniques are proposed for example neutralization lines [5], parasitic geometry [6], and ground plane modifications [7]. In microstrip antenna, there 
must be a ground layer with a distinct geometry, which has a significant effect on the performance of such antenna [8]. As in [9], a discussion of the partial ground effect is presented. Also, in [10] and [11] improved the isolation with using tree shape and serration edge of the ground, respectively. On the other hand, the use of serration edge with patch antenna can improve antenna gain, radiation pattern effect and frequency performance which depends on its dimensions [12]. Accordingly, this research will try a patch microstrip with serrated edge having special geometries and band frequency to match the future smartphone applications.

\section{Single antenna geometry}

The proposed prototype consists of three layers as shown in Figure 1. The first one contains a dual-polarized right-angled triangle with serrated chord feeding by $50 \Omega$ microstrip line and used a "Sub Miniature version A" (SMA) as a connector. The second layer with a height of 1.5 mm acts as a substrate which made of Rogers RO3003 (lossy) with permittivity 2.2 and 0.001 of tangent. The third layer which considered as a ground layer concerned with partial geometry. All details of the proposed single antenna are summarized in Table 1.

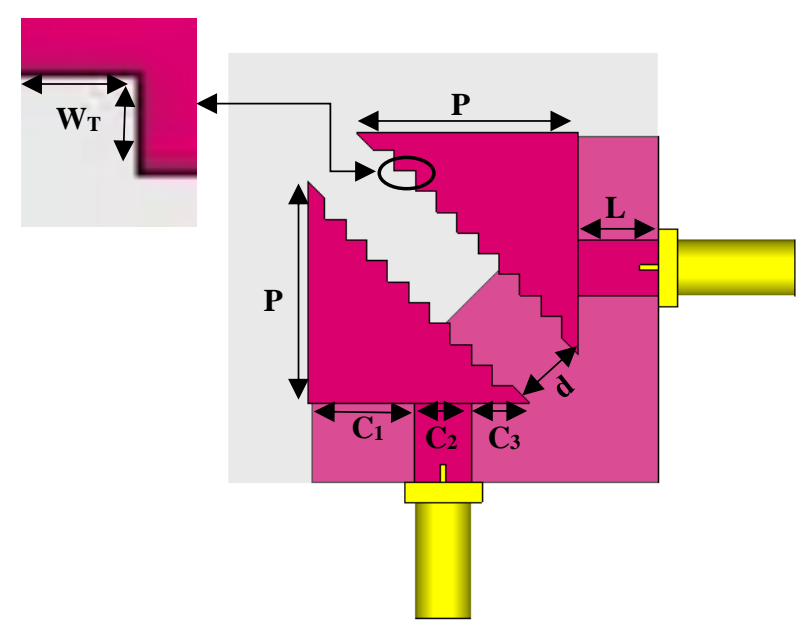

(a)

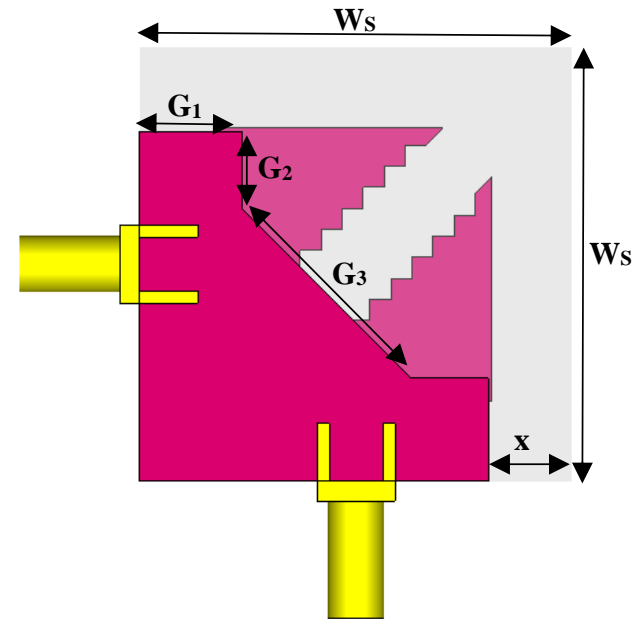

(b)

Fig. 1. Single antenna element (a) Front view and (b) Back view.

TABLE 1. Parameter values of the antenna design.

\begin{tabular}{cccc}
\hline Parameter & Value $(\mathrm{mm})$ & Parameter & Value $(\mathrm{mm})$ \\
\hline $\mathrm{P}$ & 18.04 & $\mathrm{~W}_{\mathrm{T}}$ & 1.70 \\
$\mathrm{~L}$ & 6.48 & $\mathrm{~W}_{\mathrm{S}}$ & 35 \\
$\mathrm{~d}$ & 5.60 & $\mathrm{G}_{1}$ & 8.30 \\
$\mathrm{C}_{1}$ & 8.70 & $\mathrm{G}_{2}$ & 6.23 \\
$\mathrm{C}_{2}$ & 3 & $\mathrm{G}_{3}$ & 19.33 \\
$\mathrm{C}_{3}$ & 4.74 & $\mathrm{X}$ & 6.80 \\
\hline
\end{tabular}


The procedure of the current design is started with choosing the shape of microstrip similar to the proposal in [10], but our modification is detailed by using polarization diversity instead of spatial diversity and study the effect of distance between the two triangles in order to investigate a better mutual coupling between them. furthermore, this research applied the serrated chord and partial ground geometry.

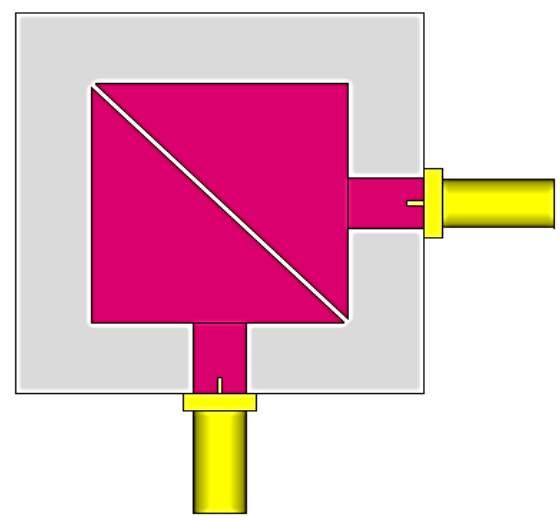

Fig. 2. First step of design with no serrated edge.

Figure 2 shows the first step of a single antenna element design. The distance between the two corresponding triangles is studied to show the effect of separation distance on its performance, the four results which have been chosen are illustrated in Figure 3.

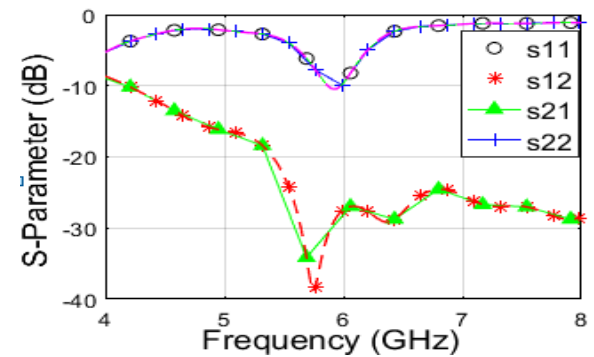

(a)

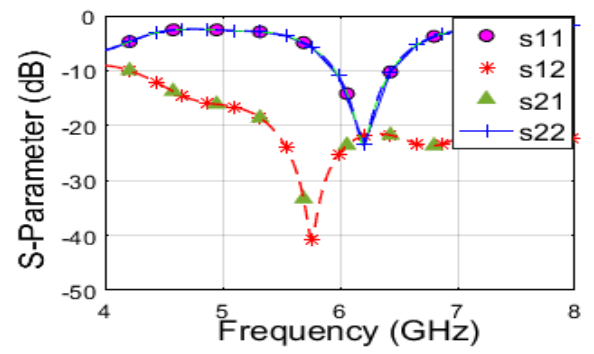

(c)

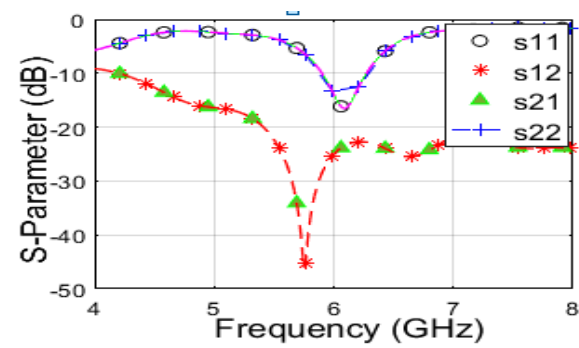

(b)

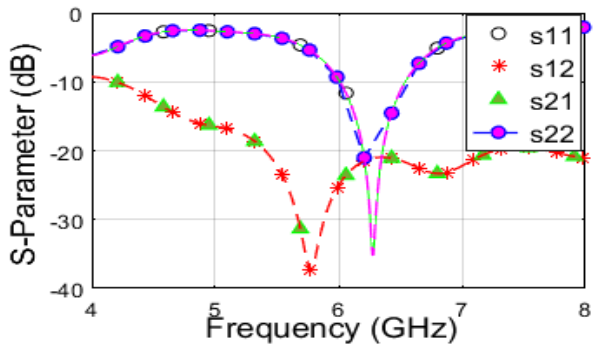

(d)

Fig. 3. S-Parameter results for first step of antenna with different $d$ in $\mathrm{mm}$ (a) $d=4$, (b) $d=5$, (c) $d=5.6$ and (d) $d=6$. 
The result of Figure 3 (C) shows mostly suitable with return losses of approximately $-24 \mathrm{~dB}$ and a mutual coupling about $-23 \mathrm{~dB}$. From other view, a survey of many researches whose deal with serrated design in [12-13] show that the serrated shape has improved the gain and frequency performance. Accordingly, this research applies such shape in order to approach prefer performance in term of antenna gain and frequency response. The effect of $\mathrm{W}_{\mathrm{T}}$ length with the same $d, G_{2}$ and $G_{3}$ is tried with multiple values that obtained the results shown in Figure 4.

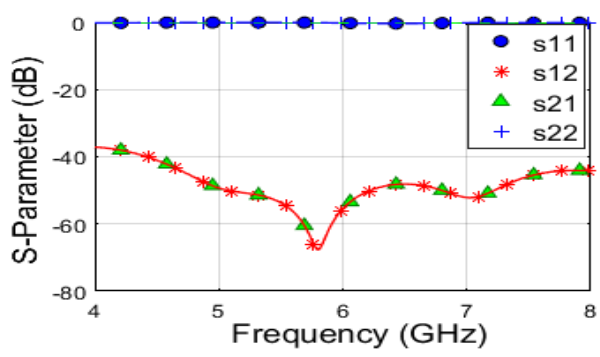

(a)

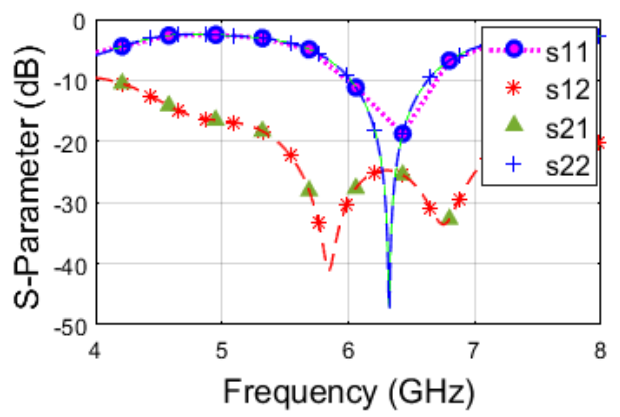

(c)

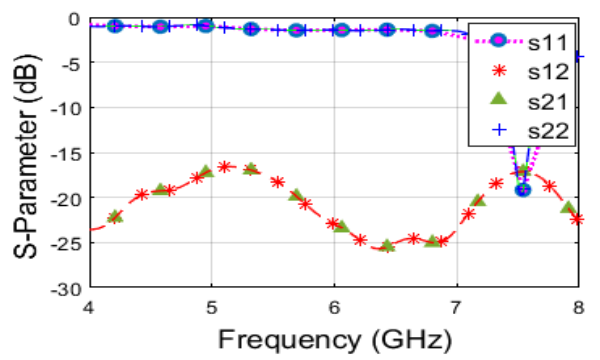

(b)

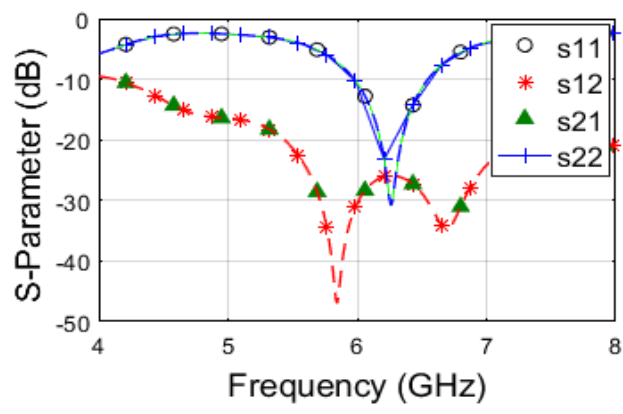

(d)

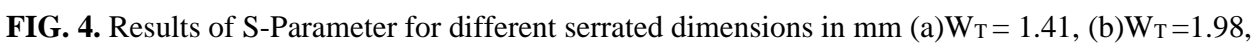
(c) $\mathrm{W}_{\mathrm{T}}=1.90$, and $(\mathrm{d}) \mathrm{W}_{\mathrm{T}}=1.70$.

The results of Figure 4 (d) with a return loss of about $-32 \mathrm{~dB}$ and isolation $-26 \mathrm{~dB}$ confirms that the better length of $\mathrm{W}_{\mathrm{T}}$ is $1.7 \mathrm{~mm}$. Although the result of Figure 4 (c) shows return losses can be approach $-50 \mathrm{~dB}$ but the isolation is $-25 \mathrm{~dB}$, so that, Figure 4 (d) is still as the best result. On the other hand, the dimension of the partial ground has direct effect on the result. [5] Figure shows four samples among many trying dimensions, we choose four among them. 


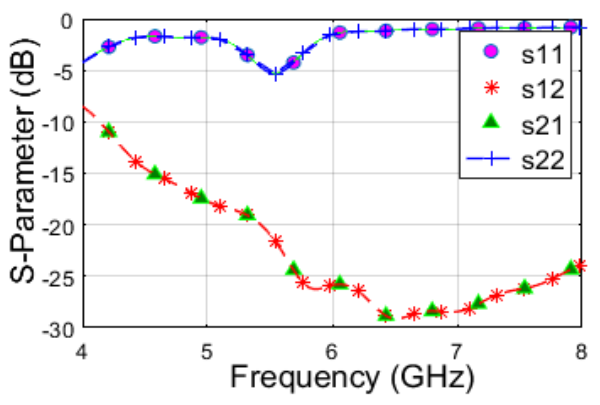

(a)

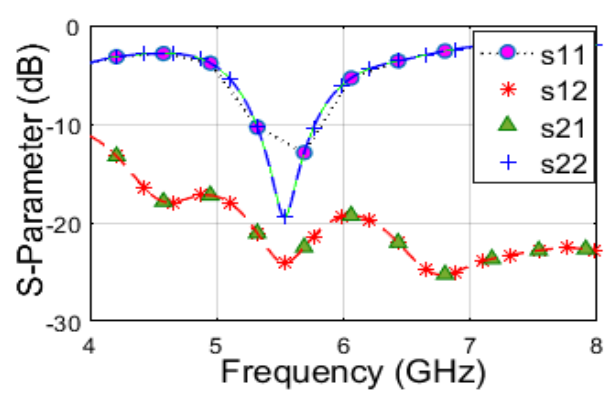

(c)

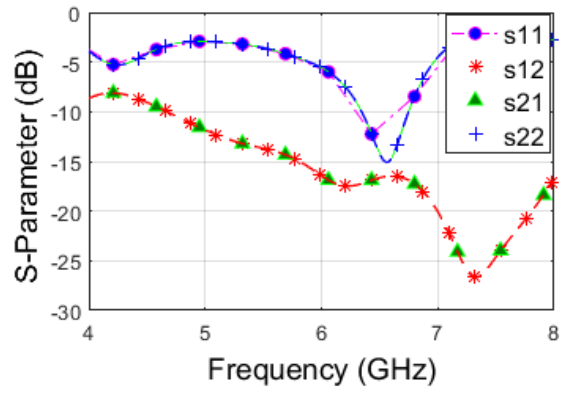

(b)

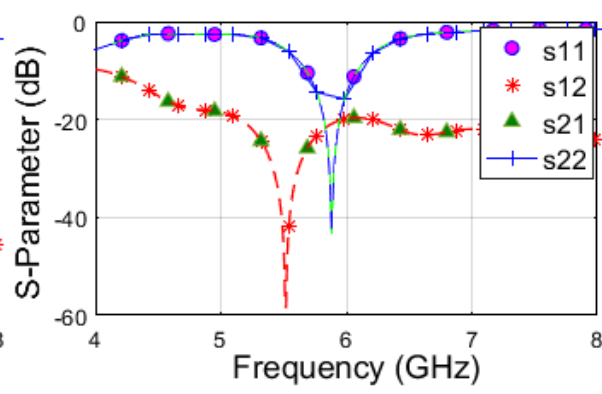

(d)

Fig. 5. The effect of G2 and G3 on S-Parameter (a) 28.14, 0, (b) 12, 15, (c) 7.44, 8.33, and (d) 6.60, 23 respectively.

The result shows that the proposed single antenna element is operated at $6.243 \mathrm{GHz}$ and can cover $590 \mathrm{MHz}(5.97 \mathrm{GHz}-6.56 \mathrm{GHz})$ at $-10 \mathrm{~dB}$, while the bandwidth has wider at $-6 \mathrm{~dB}$ about $1.03 \mathrm{GHz}$ in the range of (5.75-6.78) GHz. Also, the result of VSWR shows that it doesn't approach $2 \mathrm{~dB}$ for both exciting ports as illustrated in Figure 6.

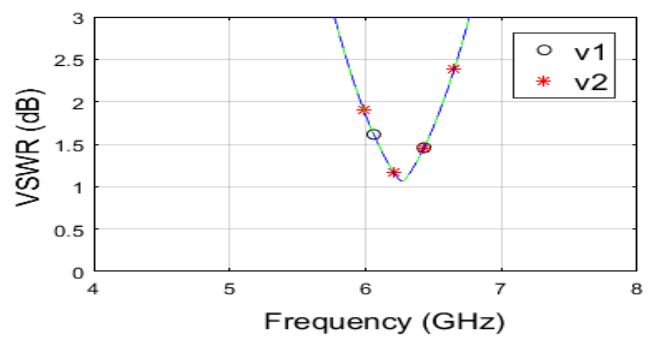

Fig 6. VSWR for the proposed antenna

In term of the radiation pattern, Figure 7 determined the radiation shape for each port, which form an oval shape covering all direction of the antenna with a gain of $4.85 \mathrm{dBi}$ for both ports. 


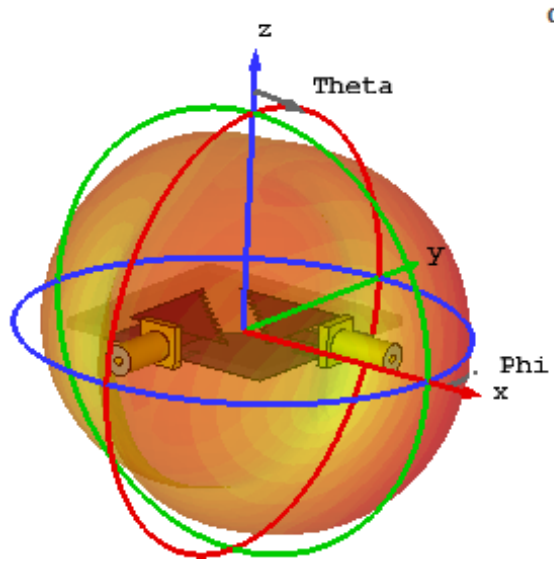

(a)

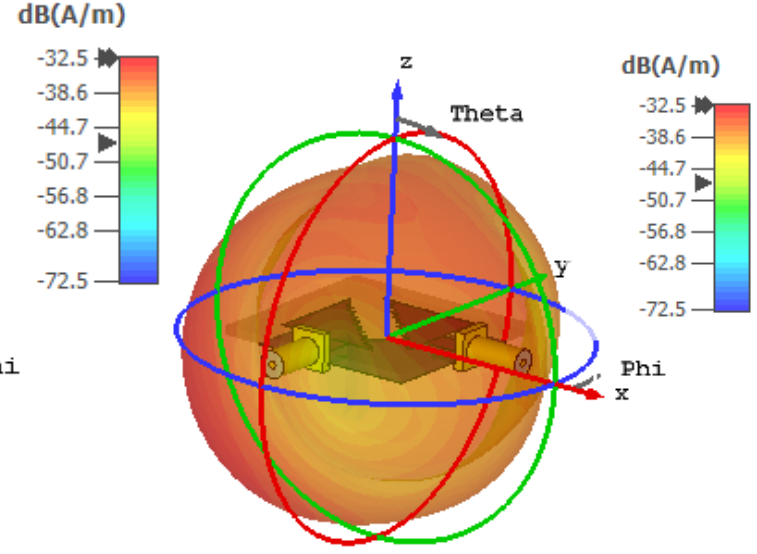

(b)

Fig. 7. Radiation pattern for single antenna element (a) Port1 and (b) Port (2).

\section{MIMO antenna array}

For the purpose of the smart mobile applications which need to cover all directions of the device body, an antenna array is proposed to install four antenna elements which were designed in section 2. At first, trying design steps, each antenna element installed in a corner of a PCB which made of Rogers RO3003 (lossy) with permittivity 2.2 and 0.001 tan $\delta$. In this research, the ground layer is separated only with the corresponding of the antenna elements in order to improve the reflection coefficients $S_{\mathrm{ab}}$ and mutual coupling $\mathrm{S}_{\mathrm{rk}}$. Now, the final proposed MIMO paradigm is obtained a better result in terms of $S_{a b}$ and $S_{r k}$ as shown in Figure 8.

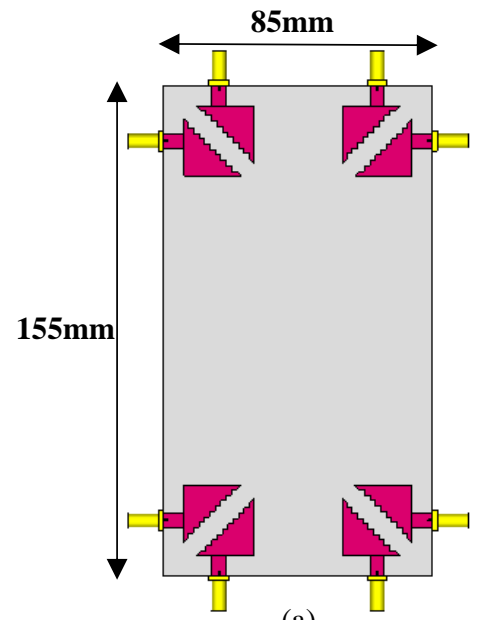

(a)

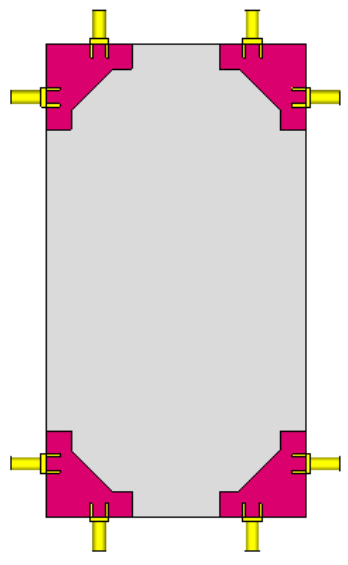

(b)

Fig. 8. The proposed smartphone antenna system (a) Front view and (b) Back view. 
When all ports excited simultaneously, the system can obtain an operating frequency of 6.123 GHz with $S_{\text {rk }}$ under $-20 \mathrm{~dB}$ as in Figure 9.

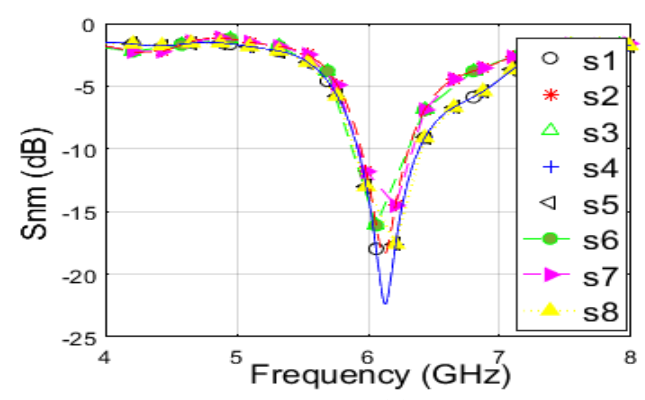

(a)

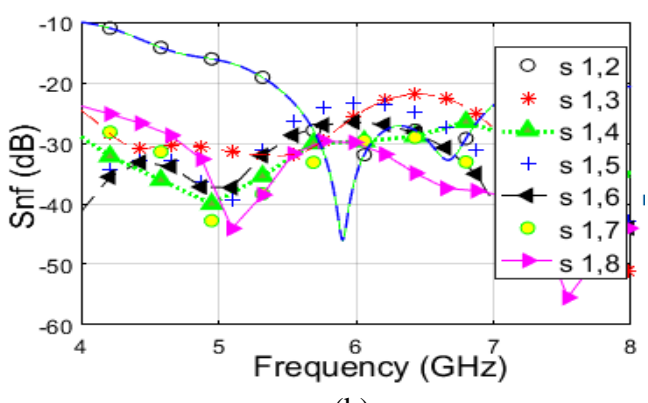

(b)

Fig. 9. Results of smartphone antenna system (a) Return losses and (b) Mutual coupling.

On the other hand, Figure 10 shows the VSWR for all excited ports in MIMO antenna array.

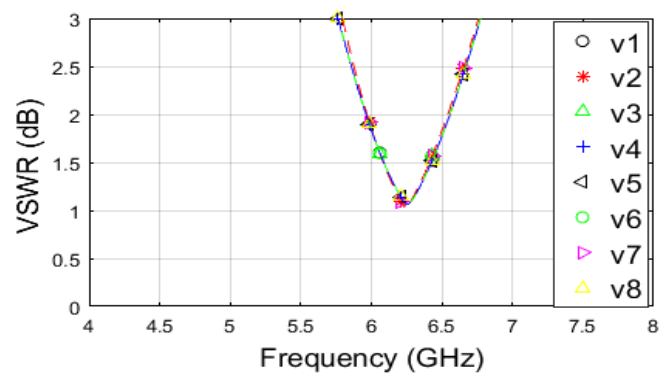

Fig. 10. VSWR of MIMO antenna array.

Also, Figure 11 shows the radiation pattern when all port operated at the same time, it obviously appears the distribution for all ports can over all directions of device body.
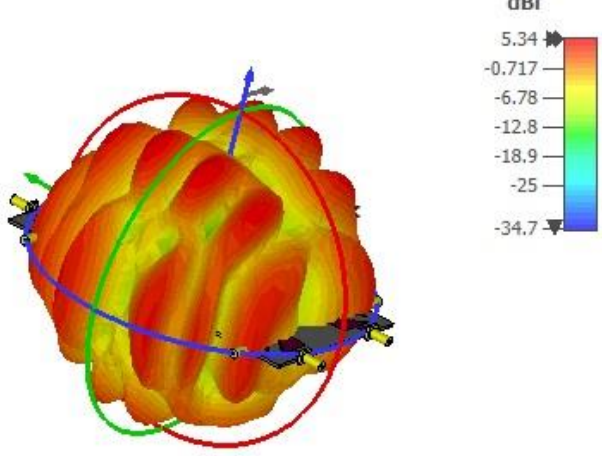

Fig. 11. Radiation pattern for MIMO antenna array.

4 Conclusion. In this research, a model of MIMO array of dual polarized four elements is proposed to match the future smartphone. Such model is obtained after a 
procedure of trying several dimensions started with the separation between two rightangle triangles. The chord of each triangular has a serrated shape which affects the radiation pattern, improves gain and enhances the frequency performance. Several trying to choose an optimum of serrated length to obtain a better response. Also, several dimensions of partial ground are experienced to achieve better overall results. The final proposed MIMO prototype shows that the operating frequency is $6.13 \mathrm{GHz}$ with a bandwidth of $500 \mathrm{MHz}(5.9-6.4) \mathrm{GHz}$ at $-10 \mathrm{~dB}$ while the single element operated at $6.27 \mathrm{GHz}$ and cover $590 \mathrm{MHz}(5.97 \mathrm{GHz}-6.56 \mathrm{GHz})$ at $-10 \mathrm{~dB}$.

\section{Reference}

[1] W. Su, Q. Liu, H. He, and H. Zhang: A new context awareness scheme for multi-mode mobile terminals in mobile Internet. IET 3rd Int. Conf. IET Wireless, Mobile Multimedia Netw. (ICWMNN). pp. 95-98 (2010).

[2] N.Al-Falahy and O.Y.Alani: Technologiesfor5Gnetworks:Challenges and opportunities. IT Prof. pp. 12-20 (2017).

[3] M.A. Jensen and J.W. Wallace: A review of antennas and propagation for MIMO wireless communications. IEEE Trans. Antennas Propag. pp. 2810-2824 (2004).

[4] Jacob C. Coetzee and Yantao Yu: Design of Decoupling Networks for Circulant Symmetric Antenna Arrays. IEEE Antennas and Wireless Propagation Letters. pp. 291-294 (2009).

[5] Y.-L. Ban, Z.-X. Chen, Z. Chen, K. Kang, and J. L.-W. Li: Decoupled hepta-b and antenna array for WWAN/LTE smartphone applications. IEEE Antennas Wireless Propag. Lett. pp. 999-1002 (2014).

[6] Naser Ojaroudi Parchin, Yasir Ismael Abdulraheem Al-Yasir, Ammar H. Ali, Issa Elfergani, James M. Noras, Jonathan Rodriguez and Raed A. Abd-Alhameed: Eight-Element DualPolarized MIMO Slot Antenna System for 5G Smartphone Applications. IEEE Access._pp. 15612 - 15622 (2019).

[7] C.-Y. Chiu, C.-H. Cheng, R. D. Murch, and C. R. Rowell: Reduction of mutual coupling between closely-packed antenna elements. IEEE Trans. Antennas Propag. pp. 1732-1738 (2007).

[8] Ajit Mali Vasekar, and Mahesh Mathpati: Effect of Ground Plane Size on Metamaterial Based Patch Antenna. International Journal of Electrical, Electronics and Data Communication. pp. 2320-2084 (2018).

[9] Shereen Shandal, Yaqeen Mezaal, Mahmood Mosleh and Mohammed Kadim: Miniaturized Wideband Microstrip Antenna for Recent Wireless Applications. Advanced Electromagnetics. pp. 7 - 13 (2018).

[10] Shuai Zhang, Zhinong Ying, Jiang Xiong, and Sailing He: Ultrawideband MIMO/Diversity Antennas with a Tree-Like Structure to Enhance Wideband Isolation. IEEE Antennas and Wireless Propagation Letters. pp. 1279 - 1282 (2009).

[11] G. H. Huff and J. T. Bernhard: Improvements in the Performance of Microstrip Antennas on Finite Ground Planes Through Ground Plane Edge Serration. IEEE Microwave and Wireless Components Letters. pp. 308 - 310 (2002).

[12] Alp Metin, Demet Delikanli, İsmail Kaya , Selim Keskiner ,Taha Imeci , and Tahsin Durak: Serration Effect On Gain For Microstrip E-Shape Patch Antenna. IEEE/ACES International Conference on Wireless Information Technology and Systems (ICWITS) and Applied Computational Electromagnetics, pp.1259-1260 (2016).

[13] Mohammed Aboud Kadim, Mahmoud F. Moslah, Shereen Abdalkadum Shandal, Yaqeen Sabah Mezaal: New Compact Wideband Microstrip Antenna for Wireless Applications. Advanced Electromegnatic. pp. 85- 92 (2018). 
